\title{
Liver Dysfunction in Sternness Burn Injury in Association to Age Estimate: A Conceivable Role of Antioxidant Biomarker and Tumor Necrosis Factor Alpha
}

\author{
Eman A. A. Abdallah*, Nermien A. Ibrahim, Nadra A. Kandeel \\ Forensic Medicine and Clinical Toxicology, Faculty of Medicine, Zagazig University, Egypt \\ Email: *dr.emanabdallah1983@gmail.com
}

How to cite this paper: Abdallah, E.A.A., Ibrahim, N.A. and Kandeel, N.A. (2022) Liver Dysfunction in Sternness Burn Injury in Association to Age Estimate: A Conceivable Role of Antioxidant Biomarker and Tumor Necrosis Factor Alpha. Journal of Biosciences and Medicines, 10, 111-123.

https://doi.org/10.4236/jbm.2022.102011

Received: January 15, 2022

Accepted: February 18, 2022

Published: February 21, 2022

Copyright $\odot 2022$ by author(s) and Scientific Research Publishing Inc. This work is licensed under the Creative Commons Attribution International License (CC BY 4.0).

http://creativecommons.org/licenses/by/4.0/

\begin{abstract}
Background: Burn injuries represent one of the greatest public health problems that induce significant patient morbidity and mortality. Scalds are the most common cause of burn injuries which is known to have long term grave consequences on general health. Aim: The current study was performed to identify the age of scald burn from histopathological changes and TNF- $\alpha$ immunoexpression. As well, study the probable relation between the scald age and the hepatic function impairment. Materials and Methods: A total number of 40 adult male albino rats were used in the study. Eight kept as control group I. Thirty-two rats were exposed to scald injury involving $20 \%$ of total body surface area (TBSA). Histopathological examination for the scald area, liver, and skin TNF- $\alpha$ immunohistochemistry was performed. Liver function tests and liver tissue malondialdehyde (MDA) were also determined. The study was carried out after 2, 7 days, 1 and 3 months of scald incidence. Results: Progressive histopathological changes and elevated liver enzymes were observed in the early scald ages while manifestations of healing and improvement in liver parameters, started to occur after 1 and 3 months of scald infliction in comparison with the other periods. There was a highly significant $(\mathrm{P}<0.001)$ increase in malondialdehyde level and TNF- $\alpha$ expression in scald injured groups after 2 and 7 days compared with control group I. Conclusion: Overall, the results showed the ability to identify the age of scald injury using routine histopathological examination. Also, scald injury involving $20 \%$ of TBSA may cause long term impairment of hepatic function. Moreover, the proinflammatory results revealed that TNF- $\alpha$ may consider as mediators in the post-burn pathophysiological process. Furthermore, our results declare a significant correlation between MDA levels and the degree of burn complications, including shock and remote organ damage.
\end{abstract}




\section{Keywords}

Scald, TNF- $\alpha$, Histopathology, Hepatic Function, MDA

\section{Introduction}

Burn injuries are the most violent types of injuries and are not easy to analyze. It represents a terrible psychological, medical, and public health problem. It occurs as a consequence of mechanical products, electrical or thermal which have a high influence on skin and tissues. Likewise, the crime scenes due to the burning in all cases are the critical evidence of injuries and considered sensitive and sophisticated in such cases [1].

The basis of burn classification is depth throughout examination, assessed through the following four elements: appearance, blanching to pressure, pain, and response to sensation. The American Burn Criteria uses those four components to categorize burns according to the thickness. Third degree is a full thickness burn destroying all the skin layers till below hair follicles, sweat glands and subcutaneous fat tissue, accordingly, it is usually not painful due to destruction of the nerve endings [2]. The frequency of burn injury is not restricted to any population or certain age group, but the forensic medicine is involved if the incidence of burns has been attributed to violence, abuse, neglect, or due to torture [3].

Scalding is a form of a thermal burn resulting from heated fluids such as boiling water or steam. It can be seen in the 2 nd or 3rd-degree burns. It is caused by the application of liquid near boiling point or from steam. Blisters are considered a crucial character of scald burn injury. It can be fatal injury as the tissues and cells of the skin are completely exposed to these injuries [4]. Scalding burns are divided into three types: immersion in a hot liquid whether accidental or deliberate, splash (or spill) burns which are mostly accidental, finally steam burns i.e., exposure to superheated steam. Hot water is found to be the most common cause of the immersion, spill, and splash burns [5].

It was established that cytokines production is greatly affected by burn injury, also, adrenal, and gonadal steroids are affected, resulting in sex-related disturbances following burn injury [6]. Cytokines have been supposed to raise in the serum of burn patients. Inflammatory mediators' levels for example tumor necrosis factor alpha (TNF- $\alpha$ ), interleukin-6 (IL-6), and interleukin-8 (IL-8) were observed to be elevated after burn injuries. TNF- $\alpha$ is secreted mainly by activated macrophages and although it is primarily involved in inflammation and immunity, it has also been found to play a role in the process of angiogenesis. Also, they may cause a failure of different organ systems, at least in part, due to increased apoptotic cell death [7].

The present experimental study was carried out to identify the histopathological changes of different ages of a full thickness scald injury which occupies $20 \%$ 
of the total body surface area (TBSA). As well, analyzed the possible relation between the scald age and the hepatic function impairment. Moreover, Immunohistochemical of skin TNF alpha, liver biochemical parameters and biomarker of oxidative stress Malonaldehyde (MDA), will be assessed which would be beneficial and necessary to figure out the association between multiorgan dysfunction and burn crises.

\section{Materials and Methods}

\subsection{Animals}

Forty adult albino rats were used throughout this study. Eight albino rats designated as control group I, received only regular diet and tap water to measure the basic parameters. The remaining 32 rats were subjected as a model for scald injury and sacrificed by cervical dislocation [8], divided into four different scald ages groups: 2, 7 days, 1 and 3 months of injury infliction group II, III, IV, V respectively, (8 albino rats/scald age).

This study was carried out in accordance of Institution Review Board (IRB) of Faculty of Medicine, Zagazig University approval. Forty adult male albino rats were obtained from the animal house of the Faculty of Veterinary Medicine, Zagazig University; their weights were chosen to range between 290 and 310 gm. The procedures affirmed according to "The Guide for the Care and Use of Laboratory Animals" (Institute of Laboratory Animals Resources, 1996) [9]. This will be concern the care of the experimental animals used in the present study.

\subsection{Chemicals}

In the current burn model we used ketamine hydrochloride (K2753) and diazepam (D0899) which were obtained from Sigma-Aldrich Chemical Company.

\subsection{Scald Animal Model}

Separately, each rat was anesthetized, and the analgesic was given with intraperitoneal injection of ketamine hydrochloride $(20 \mathrm{mg} / \mathrm{kg} \mathrm{BW})$ and diazepam $(0.1$ $\mathrm{mg} / \mathrm{kg} \mathrm{BW}$ ). The back and flank skin of the rats was cleanshaven. A plaster cast was designed with an opening allow the hot water to reach the exposed area of the rat back below the neck when immersed in hot water. Rats exposed to a hot water $\left(100^{\circ} \mathrm{C}\right)$ for 10 seconds [10]. This should produce a nonlethal full thickness injury to the skin which covers $20 \%$ of the total body surface area which was calculated according to Lee formula: total body surface area (TBSA) $=($ body weight in grams $\times 0.78)+148$ [11]. TBSA of a rat weighing 300 grams is 382 $\mathrm{cm}^{2}$. So that $20 \%$ of TBSA equals $76.4 \mathrm{~cm}^{2}$.

\subsection{Histopathological Examination}

Light microscopic examination was performed to distinguish histopathological changes of the skin and the liver with scald injury. The skin affected with scald burn was dissected and Bouin's solution (Sigma-Aldrich Chemical Company) 
used for fixation in different scald ages 2, 7 days and 1, 3 months [12], however $10 \%$ formalin saline for liver specimen's fixation was applied. Furthermore, skin and liver were embedded in paraffin blocks. Sections in $5 \mu$ thickness were prepared for examination. Hematoxylin and Eosin staining (Sigma-Aldrich) was used for these sections according to the method described by Wilson \& Gamble [13]. TNF- $\alpha$ Immunohistochemical recognition determined according to the method explained by Carreiraa et al. Staining was considered positive if the tissue demonstrated brown staining [14].

\subsection{Detection of Serum Biochemical Parameters}

Venous blood samples were collected from the retro-orbital plexus of the animals by capillary glass tubes using light ether anesthesia (Sigma-Aldrich) according to method explained by Joslin [15]. According to the manufacturer's procedures (Abcam company-ab105134, Sigma Aldrich-MAK055), for each animal, $1 \mathrm{ml}$ of blood was collected into a glass tube for the quantitative measurement of liver function parameters in rat's different groups.

\subsection{Determination of Malondialdehyde (MDA) in Liver Tissue}

The weight of liver homogenized using $0.9 \%$ saline concentration (the time of the volume is 9:1). $10 \%$ homogenate pass to centrifuging process for $10 \mathrm{~min}$ (3000 $\mathrm{rpm} / \mathrm{min})$. The supernatant was diluted with 10 times of the volume of $0.9 \%$ saline to $1 \%$ concentration [16]. Aspirated supernatants added to $2.5 \mathrm{~mL}$ of $20 \%$ Trichloroacetic acid (TCA) and $1 \mathrm{~mL}$ of $0.67 \%$ Thiobarbituric acid (TBA) (Sigma-Aldrich). At $100^{\circ} \mathrm{C}$ for 30 -minute, color of TBA appeared in water. When temperature descends to room temperature, $4 \mathrm{~mL}$-butanol added, then vigorously shake it then centrifuged until pink color of butanol layer (secondary product of MDA) appeared. The absorption of end product is measured spectrophotometrically at $532 \mathrm{~nm}$ wavelength [17].

\subsection{Statistical Analysis}

Windows program SPSS 13.0 was used for statistical analysis. Data was represented in terms of means \pm SD. The differences were compared for statistical significance by ANOVA. Statistical difference between groups was calculated by LSD. Difference was considered significant at $\mathrm{p} \leq 0.05$.

\section{Results}

\subsection{Histopathological Examination}

\subsubsection{Skin Examination}

In $\mathrm{H} \& \mathrm{E}$ skin sections (Table 1, Figures 1A-I), control group I showed intact dermal epidermal layers with normal adnexal structures after 2, 7 days, 1 and 3 months. In Scald injured groups, skin with scald injury revealed ulceration of the epidermis and dermal inflammatory infiltrate that invade muscles in some area by the end of the second day group II of scalding injury. While, by the end of 
seventh day group III, there was destruction of adnexal structures, and area of coagulative necrosis invaded by inflammatory cells. Furthermore, by the end of the first month group IV, a decrease in the acute inflammatory response findings were observed with deposition of multiple collagen layers. Finally, by the end of the third month group $\mathrm{V}$, re-epithelialization was observed in the form of multiple epithelial cells islands migrating towards the wound surface from underlying dermal appendages.

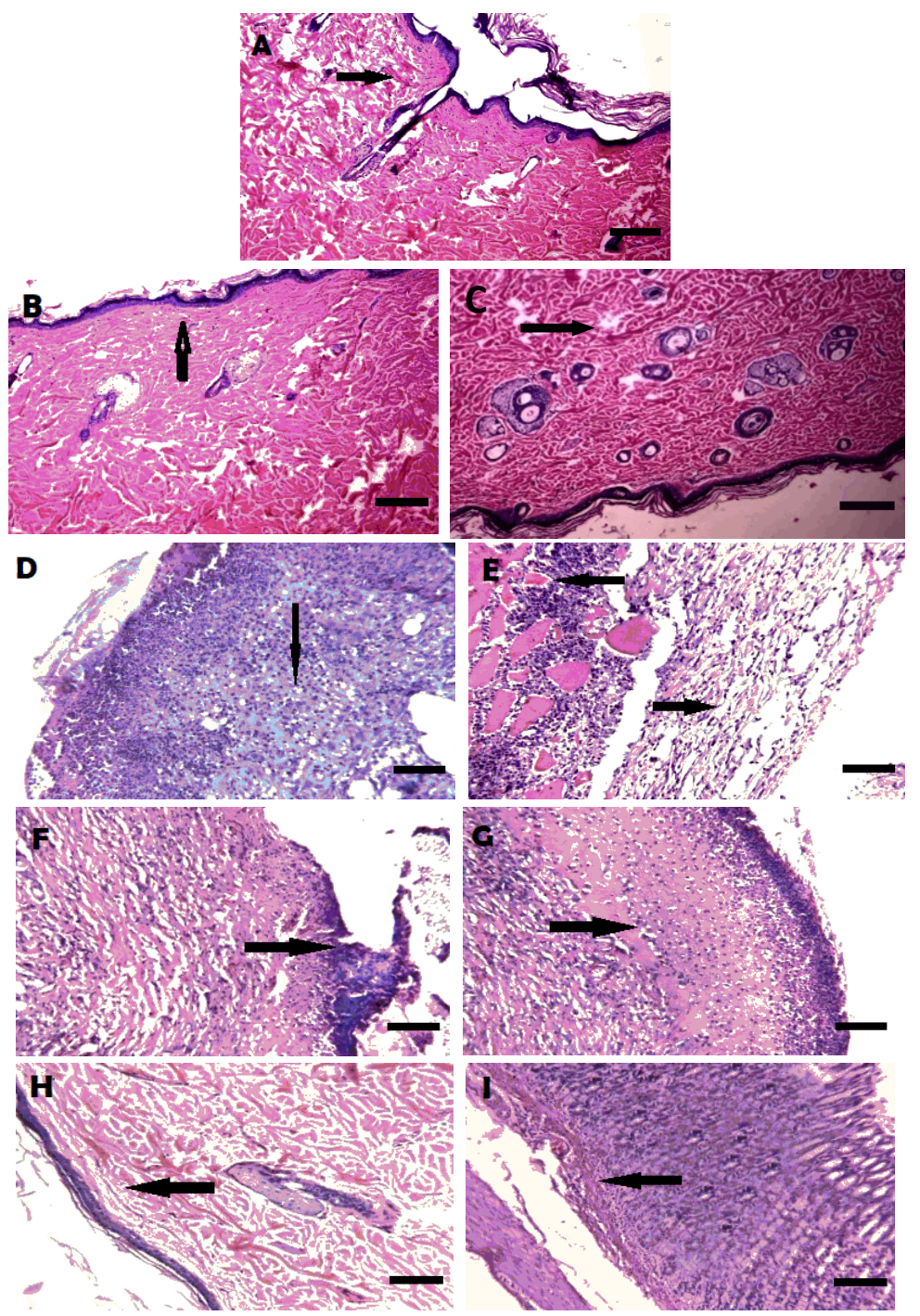

Figure 1. An $\mathrm{H} \& \mathrm{E}$ photomicrograph of a section in the skin of adult male albino rat. A, B, C: control group I showing normal epidermis, dermis and adnexal structures. D: scald injury after 2 days group II showing heavy dermal inflammatory infiltrate. E: scald injury after 2 days showing destruction of epidermis and dermis heavy dermal inflammatory infiltrate invading muscle layer. F: ulceration of the epidermis and dermis. G: scald injury after 7 days group III showing coagulative necrosis. $\mathrm{H}$ : scald injury after 1 month group IV showing destruction of skin adnexa and deposition of multiple layers of collagen. I: scald injury after 1 month group IV showing re-epithelialization with multiple islands of epithelial cells migrating to the wound surface (x 200). 
Table 1. Characteristic light microscopic findings observed in skin in terms of absent $(-)$, mild $(+)$, moderate $(++)$ and severe $(+++)$ after 2, 7 days, 1, 3 months from exposure to antemortem scald injury in adult male albino rats.

\begin{tabular}{|c|c|c|c|c|}
\hline \multirow[b]{2}{*}{ Light Microscopic Finding } & \multicolumn{4}{|c|}{ Age of Scald Injury } \\
\hline & $\begin{array}{c}\text { Group II } \\
\text { after } 2 \text { Days }\end{array}$ & $\begin{array}{c}\text { Group III } \\
\text { after } 7 \text { Days }\end{array}$ & $\begin{array}{c}\text { Group IV } \\
\text { after } 1 \text { Month }\end{array}$ & $\begin{array}{c}\text { Group V } \\
\text { after } 3 \text { Months }\end{array}$ \\
\hline Destruction of Adnexal Structures & + & ++ & + & + \\
\hline Ulceration in the Epidermis & + & ++ & + & - \\
\hline Inflammatory Infiltrate in the Dermis & ++ & +++ & - & - \\
\hline Deposition of Multiple Collagen Layers & - & - & ++ & +++ \\
\hline Re-epithelialization & - & - & + & +++ \\
\hline Multiple Cell Islands & - & - & ++ & ++ \\
\hline Epithelial Cell Migration to the Scald & - & - & + & ++ \\
\hline TNF- $\alpha$ Immunoexpression & +++ & ++ & - & - \\
\hline
\end{tabular}

\subsubsection{TNF- $\alpha$ Expression}

The TNF- $\alpha$ immunohistochemical expression performs negative in the dermis, endothelial cells and perivascular cells of the skin of the control group I after 2, 7 days, 1 and 3 months. In scald injured groups, skin showed a positive expression of TNF- $\alpha$ in the dermis, endothelial cells and perivascular cells after 2- and 7days groups II, III. Besides, at the end of 1- and 3-months groups IV and V illustrated improvement verified in skin specimens of the rats, both groups IV and $\mathrm{V}$ showed a negative expression of TNF- $\alpha$ in the dermis, endothelial cells and perivascular cells, respectively (Table 1 , Figures $2 \mathrm{~A}-\mathrm{E}$ ).

\subsubsection{Liver Examination}

The microscopic examination of stained sections of the rat's liver control group I showed normal histology of a hepatic lobule after 2, 7 days, 1 and 3 months respectively. In scald injured groups, microscopic examination of the liver revealed obvious congestion associated with widespread marked vacuolar degeneration as well as foci of spotty necrosis. Some scattered apoptotic bodies and short fibrous septae develops by the end of the second day group II of burn incidences. However, at the end of seventh day group III of burn application showed increasing in the number of Kupfer cells and hydropic degeneration. Through the end of first month group IV the same histopathological changes as those described by the end of the seventh day were noted. As well, by the end of third month group $\mathrm{V}$ microscopic examination of the liver revealed moderate congestion and widespread moderate hydropic degeneration (Table 2, Figures 3A-E).

\subsection{Biochemical Parameters in Serum Samples}

Scald injured rats' groups showed progressive significant increase $(\mathrm{p}<0.05)$ in the mean values of serum ALT, AST with significant decrease $(p<0.05)$ of total protein, albumin and globulin after 2, 7 days and 1 month of injury infliction, compared with the control group I (Table 3). Later, after 3 months of injury infliction, significant improvement $(\mathrm{p}<0.05)$ in the mean values of serum ALT, AST, total protein, albumin and globulin was recorded when compared with the 
control group level and the mean levels recorded in the earlier periods.

\subsection{Malondialdehyde in Liver Tissue}

Scald injured rats' groups showed progressive significant increase $(\mathrm{p}<0.05)$ in the mean values of serum MDA after 2, 7 days and 1 month of injury infliction, compared with the control group I level (Table 4). After 3 months of injury infliction, significant improvement $(\mathrm{p}<0.05)$ in the mean values of serum MDA was recorded when compared with the control group level and the mean levels noted in the earlier periods.

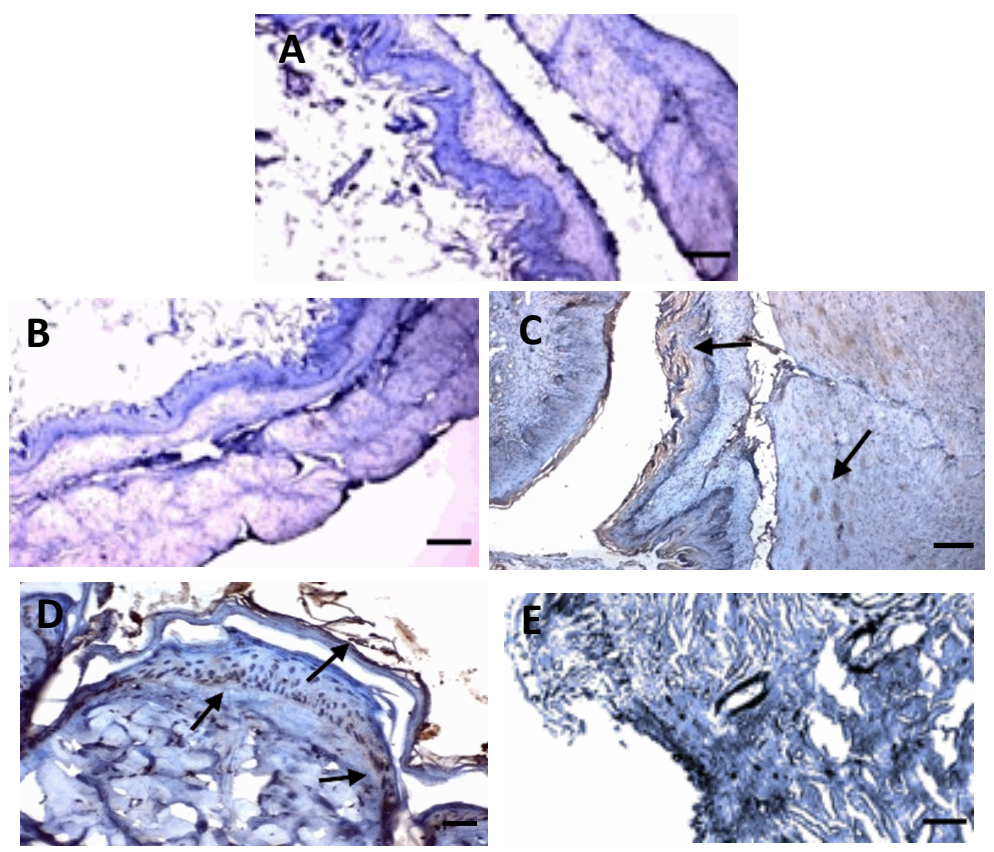

Figure 2. A DAB photomicrograph of a section in the skin of adult male albino rat showing the brown TNF- $\alpha$ immunoexpression. A: control group I showing negative expression (x 200). B: scald injury after 2 days group II showing positive expression (x 200). C: scald injury after 7 days group III showing positive expression (x 400). D: scald injury after 1 month group IV showing negative expression ( $\mathrm{x}$ 200). E: scald injury after 3 months group V showing negative expression (x 200).

Table 2. Characteristic light microscopic findings observed in the liver in terms of absent $(-)$, mild $(+)$, moderate $(++)$ and severe $(+++)$ after 2, 7 days, 1 and 3 months from exposure to antemortem scald injury in adult male albino rats.

\begin{tabular}{|c|c|c|c|c|}
\hline \multirow[b]{2}{*}{ Light Microscopic Finding } & \multicolumn{4}{|c|}{ Age of Scald Injury } \\
\hline & $\begin{array}{c}\text { Group II } \\
\text { after } 2 \text { Days }\end{array}$ & $\begin{array}{c}\text { Group III } \\
\text { after } 7 \text { Days }\end{array}$ & $\begin{array}{c}\text { Group IV } \\
\text { after } 1 \text { Month }\end{array}$ & $\begin{array}{c}\text { Group V } \\
\text { after } 3 \text { Months }\end{array}$ \\
\hline Expansion and vacuolization of hepatocytes & ++ & +++ & ++ & + \\
\hline Vascular congestion and expansion of sinusoids & ++ & +++ & +++ & + \\
\hline Increase in number of Kupffer cells & + & ++ & ++ & + \\
\hline Vacuolar degeneration & ++ & +++ & +++ & + \\
\hline Foci of spotty necrosis & ++ & ++ & +++ & + \\
\hline Hydropic degeneration & ++ & +++ & ++ & ++ \\
\hline Fibrous bands & ++ & ++ & +++ & ++ \\
\hline
\end{tabular}




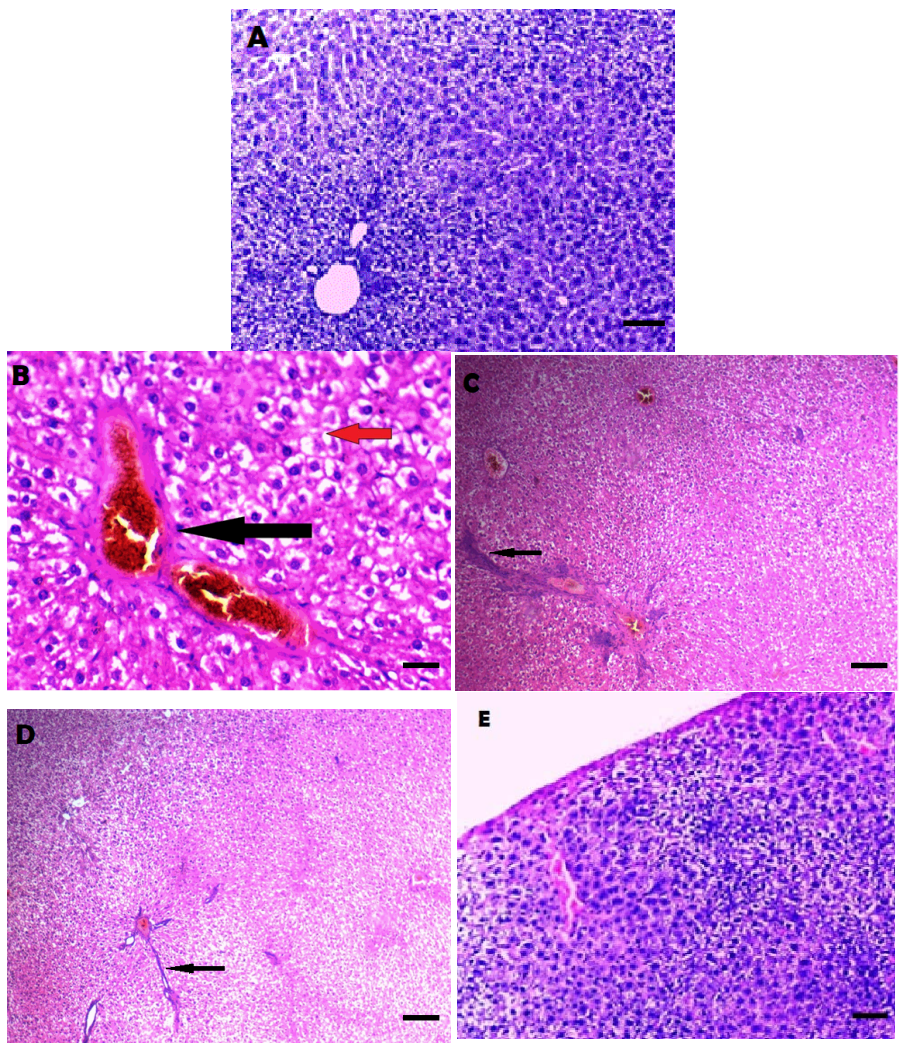

Figure 3. An $\mathrm{H} \& \mathrm{E}$ photomicrograph of a section in the liver of adult male albino rat. A: Section from control group I showing normal histology of a hepatic lobules (H\&Ex200). B: scald injury after 2 days group II showing marked congestion (black arrow) associated with widespread marked vacuolar degeneration as well as foci of spotty necrosis (red arrow). C, D: scald injury after 7 days group III showing widespread moderate hydropic degeneration; widespread spotty necrosis and fibrous bands (black arrow) H\&E (x100). E: scald injury after 1 month group IV showing moderate widespread hydropic degeneration (H\&E x400).

Table 3. Statistical comparison between mean values of aspartate-aminotransferase (AST), alanine-aminotransferase (ALT), total proteins, Albumin, Globulin levels of scald injury group after 2, 7 days, 1 and 3 months, and the percentage of change compared to mean serum level of control group using ANOVA (analysis of variance) test and least significant difference test (LSD).

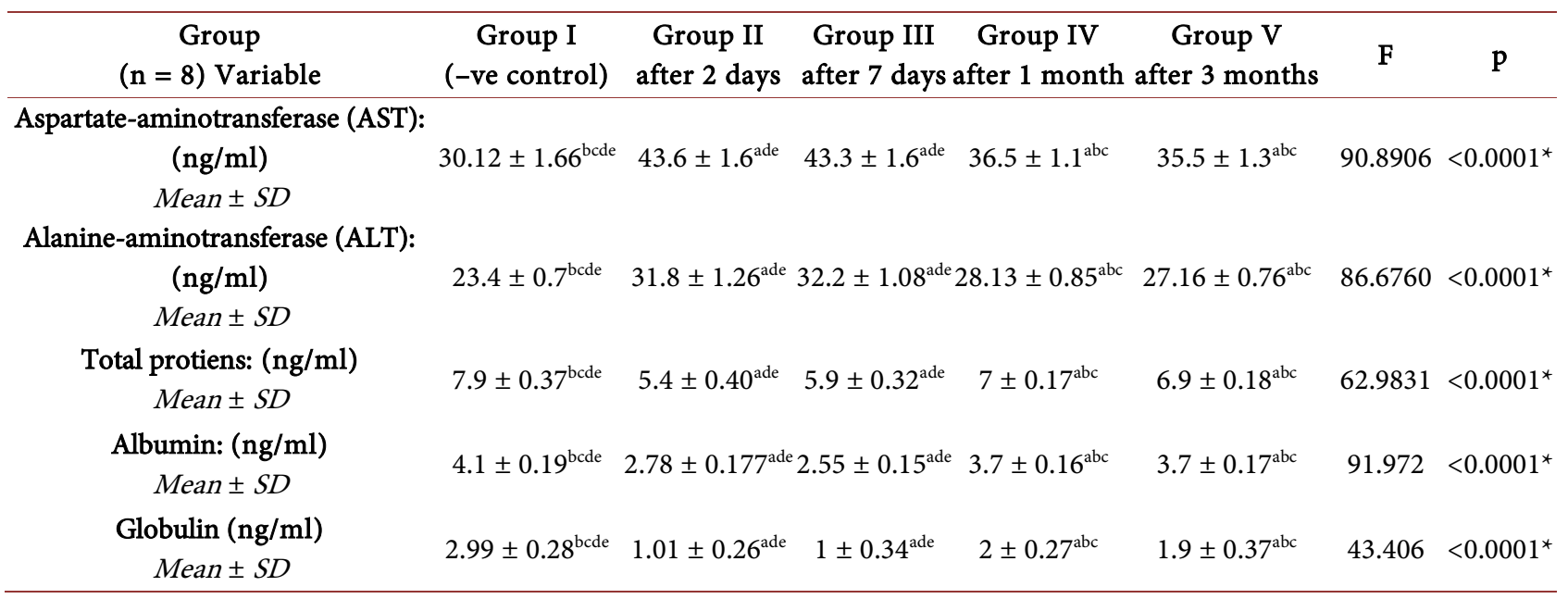

Number of rats in each group. SD: Standard Deviation. ${ }^{*}$ : highly significant $(0.0001) . \mathrm{a}=$ significant with group I. $\mathrm{b}=$ significant with group II. $c=$ significant with group III. $d=$ significant with group IV. $\mathrm{e}=$ significant with group V. 
Table 4. Statistical comparison between mean values of malondialdehyde in liver of scald injury group after 2, 7 days, 1 and 3 months, and the percentage of change compared to mean serum level of control group using ANOVA (analysis of variance) test and least significant difference test (LSD).

\begin{tabular}{cccccccc}
\hline $\begin{array}{c}\text { Group } \\
(\mathbf{n}=\mathbf{8}) \text { Variable }\end{array}$ & $\begin{array}{c}\text { Group I } \\
(- \text { ve control) }\end{array}$ & $\begin{array}{c}\text { Group II } \\
\text { after 2 days }\end{array}$ & $\begin{array}{c}\text { Group III } \\
\text { after 7 days }\end{array}$ & $\begin{array}{c}\text { Group IV } \\
\text { after 1 month after 3 months }\end{array}$ & $\begin{array}{c}\text { Group V } \\
\text { F }\end{array}$ & P \\
\hline $\begin{array}{c}\text { Malondialdehyde in liver: } \\
(\mathbf{n m o l} / \mathrm{mg}) \text { Mean } \pm S D\end{array}$ & $1.77 \pm 0.17^{\mathrm{bcde}}$ & $4.2 \pm 0.27^{\text {ade }}$ & $4.12 \pm 0.34^{\mathrm{ade}}$ & $3.33 \pm 0.13^{\mathrm{abc}}$ & $2.91 \pm 0.12^{\mathrm{abc}}$ & 119.7382 & $<0.001^{*}$ \\
\hline
\end{tabular}

Number of rats in each group. SD: Standard Deviation. ${ }^{*}$ : highly significant $(0.0001) . a=$ significant with group I. $b=$ significant with group II. $\mathrm{c}=$ significant with group III. $\mathrm{d}=$ significant with group IV. $\mathrm{e}=$ significant with group .

\section{Discussion}

Scald injury is the mostly widespread form of burn. Scalding is a form of a thermal burn resulting from heated fluids such as boiling water or steam. It can be seen in the second or third-degree of burns [18]. It has been proven that all body systems show immediate response to scald injury almost due to vascular permeability changes leading to fluid, colloid loss, and changes in physiological function of several body systems in the proceeding days [10].

In the current study, second day group II of scalding injury skin showed histopathological changes in the form of ulceration of the epidermis and severe dermal inflammatory infiltrate. At the end of seventh day group III, an area of coagulative necrosis was performed. As well, at the end of the first month group IV, healing process was observable. Moreover, re-epithelialization in the form of multiple epithelial cells islands migrating towards the wound surface from underlying dermal appendages by the end of third month group V. Our findings explained that inflammatory response is endorsed by the TNF- $\alpha$ immunohistochemical expression. These results are in accordance with Cribbs et al. who stated that the microscopic examination of skin affected by thermal injury showed blistering of the epidermal layers, epithelial cells with pyknotic nuclei, injured adnexal cells in the deep dermis, and destruction of the superficial dermal appendages [19].

Our achieved results described that the histopathological changes match with the study of Ipaktchi et al. [20] who confirmed that proinflammatory mediators stimulated grossly by burn injury from the dermis of the skin, this mechanism resulting in progressive wound inflammation and tissue edema. Furthermore, Adeteye et al. also affirmed that the full-thickness burn injury of third-degree revealed immature multiple layers of collagen fibers along with fibroblasts, numerous ulcers in the dermal layer, skin adnexal structures destruction with replacement of coagulative necrosis [21].

Moreover, Sehirli et al. revealed that burn trauma led to severe degeneration in both epidermis and dermis. Moreover, a loss and detachment of epidermis have been observed. Besides, polymorphonuclear leucocytes exhibit accumulation and congestion of blood vessels. Subsequent after six hours post burn, epithelial detachment and dermal edema were seen. Next after 48-hours of burn severe leukocyte accumulation and vascular congestion appears more visible and 
clearer [22].

Furthermore, Yongqiang et al. investigated full-thickness scald injury which was established by subjecting mouse dorsal skin to a $90^{\circ} \mathrm{C}$ water for 9 seconds. They noticed that the epidermis of scalded mouse skin was broken and become separated from the dermal layer with severe damage of hair follicles. Additionally, various regions in the subcutaneous adipose tissue showed homogenization and coagulative necrosis and apparent damage of superficial intradermal muscle layer [23].

The progressive injury occurred in consecutive days after scald burn infliction was due to coagulation of venules and capillaries contents. The effect of heat and stagnation of the tissue fluid led to inability to supply oxygen and glucose to the cells and irreversible damage occur. Secondarily, loss of water vapor through the injured surface causing dehydration of the exposed dermis [24].

Accordingly, our results showed that the TNF- $\alpha$ immunohistochemical is positively expressed in scald injury in second and seventh days of infliction. Subsequently observed negatively expressed after first and third month of scald injury age. This can be explained by the fact that cytokines are mediators in the post-burn pathophysiological process and as an important pro-inflammatory cytokine. These findings were proved with Kubo et al. who revealed that TNF- $\alpha$ gene expression (together with other cytokines) increased significantly from 3 or 6 hours to 12 hours or 1 day (inflammatory phase) and from 3 or 5 days to 7 days (proliferative phase) [25].

The current study findings revealed that two- and seven-day post injury show presence of erythrocytes in sinusoidal space associated with inflammatory infiltrate. This is in consistent with Bortolin et al. who described hepatic histopathological finding in his study four days post burn and showed the presence of erythrocytes in sinusoidal space associated with inflammation. However, fourteen days later, liver showed degeneration of the hepatocytes with inflammatory cells rounding them [26]. Similarly, Jayaraman et al. proved that the inflammatory process that appeared throughout the studied periods as well as hepatocyte degeneration increased the amount of connective tissue 14-day post injury [27].

Mostly, the first hours in incident of sever burn, the systemic signs manifested are linked to enlarged systemic capillary permeability with protein escapement into the interstitial space. Likewise, stress, inflammation and hypermetabolism arise as a consequence of large surface area burn. In addition, the circulatory response associated altered glycolysis, proteolysis, glycogenolysis, gluconeogenesis and lipolysis [28]. Our existing results are in consistent with this stress response of liver after burn injury.

As hepatic protein concentration in severely burned rats was significantly reduced, it was suggested that the liver weight gain is due to increased edema formation instead of increases in the number of hepatocytes or levels of protein. Hepatic cell damage, with release of hepatic enzymes also occurs due to edema formation [29]. In accordance with the current study also Colton et al. observed that serum AST and ALT increased during the first day after burn injury. Liver 
enzymes, such as aspartate aminotransferase (AST) and alanine aminotransferase (ALT) are the most sensitive indicators of hepatocyte injury [30].

Generally, AST and ALT are low in concentrations. Whereas these enzymes are elevated in patient serum after any cellular injury or defect in cell membrane permeability, that allow the enzymes to leak into circulation. The ALT is the more sensitive and specific test for hepatocyte injury as we also found elevated AST in case of cardiac arrest or muscle injury [30]. In addition, liver proteins in our study were significantly decreased which in accordance with Ramzy et al. who stated that increased hepatocyte proliferation is a compensation mechanism of the liver against apoptosis. Regrettably, the liver fails to recover hepatic mass and protein concentration [31].

Finally, Malonaldehyde levels in the liver tissues of group II, III and IV were found to be significantly higher than those of the control group I ( $p<0.001$ ), which agree with the results of Sehirli et al. who clarified that formation of malondialdehyde is a major indicator of oxidative injury as an end product of lipid peroxidation. Evidence suggested that there is a correlation between the tissue MDA levels and the degree of burn complications, including shock and remote organ damage [22].

Taken together, our findings shed the attention that identifying the age of scald injury can be performed using routine histopathological examination. Also, to discover the relation between scald burn and liver dysfunction that may be the main cause of morbidity and mortality.

\section{Conclusion}

Conclusively, a severe burn represents a devastating injury affecting nearly all organ systems and leading to significant morbidity and mortality. Identifying the age of scald injury can be performed using routine histopathological examination. Moreover, a full-thickness scald injury involving 20\% of TBSA can cause long term impairment of hepatic functions with increased hyper-metabolic state, inflammation, catabolism and organ dysfunction. We, therefore, believe that the liver is central for postburn outcome, and we propose that attenuation of liver damage and restoration of liver function will improve morbidity and mortality of severely burned patients.

\section{Acknowledgements}

Authors would like to thank Dr. Mai Abd-Elwahab, Faculty of Medicine, Zagazig University, for her kindly assistance in the histopathological part of this study.

\section{Conflicts of Interest}

The authors declare no conflicts of interest regarding the publication of this paper.

\section{References}

[1] Sonone, S., Kumari, M. and Kumar, A. (2020) Burn Injuries and Its Medicolegal 
Importance in Indian Scenario. International Medicolegal Report Journal, 3, Issue 2, 40-50.

[2] Warby, R. and Maani, C.V. (2021) Burn Classification. Stat Pearls.

[3] Jeschke, M.G., Van Baar, M.E., Choudhry, M.A., Chung, K.K., Gibran, N.S. and Logsetty, S. (2020) Burn Injury. Nature Reviews Disease Primers, 6, 11. https://doi.org/10.1038/s41572-020-0145-5

[4] Nguyen, C.M., Chandler, R., Ratanshi, I. and Logsetty, S. (2020) Handbook of Burns. Vol. 1, 529-547. https://doi.org/10.1007/978-3-030-18940-2_42

[5] Jewo, P.I., Duru, F.I., Fadeyibi, I.O., et al. (2010) The Protective Role of Ascorbic Acid in Burn-Induced Testicular Damage in Rat. Burns, 38, 113-119. https://doi.org/10.1016/j.burns.2011.02.009

[6] Dewan, M.D., Sumsuzzman, Jeonghyun, C., Zeeshan, A.K. and Yonggeun, H. (2020) Protective Effects of Melatonin against Severe Burn-Induced Distant Organ Injury: A Systematic Review and Meta-Analysis of Experimental Studies. Antioxidant, 9, 1196. https://doi.org/10.3390/antiox9121196

[7] Abdel-Hafez, N.M., Saleh, H.Y. and El-Metwally, T.H. (2007) A Study on Biomarkers, Cytokines, and Growth Factors in Children with Burn Injuries. Annals of Burns and Fire Disasters, 20, 89-100.

[8] Tomita, Y., Nihira, M., Ohno, Y. and Sato, S. (2004) Ultrastructural Changes during in Situ Early Postmortem Autolysis in Kidney, Pancreas, Liver, Heart and Skeletal Muscle of Rats. Legal Medicine (Tokyo), 6, 25-31. https://doi.org/10.1016/j.legalmed.2003.09.001

[9] Institute of Laboratory Animal Resources, Commission on Life Sciences, National Research Council (1996) Guide for the Care and Use of Laboratory Animals. National Academy Press, Washington DC.

[10] Jewo, P.I., Duru, F.I., Osinubi, A.A., et al. (2011) Histological Changes and Testicular Dysfunction in Severely Burned Rats. Burns, 4, 227-233.

https://doi.org/10.3889/MJMS.1857-5773.2011.0171

[11] Gouma, E., Simos, Y., Verginadis, I., et al. (2012) A Simple Procedure for Estimation of Total Body Surface Area and Determination of a New Value of Meeh's Constant in Rats. Laboratory Animals, 46, 40-45. https://doi.org/10.1258/la.2011.011021

[12] Prophet, E.B., Mills, B. and Arrington, J.B (1992) Laboratory Methods in Histology. Armed Forces Institute of Pathology, Washington DC.

[13] Wilson, I. and Gamble, M. (2002) The Hematoxylins and Eosins. In: Bancroft, J.D. and Gamble, M., Eds., Theory and Practice of Histological Techniques, 5th Edition, Churchill Livingston, Elsevier Science Limited, London, 125-138.

[14] Carreiraa, R.P., Santanaa, I., Piresa, M.A., et al. (2012) Localization of Tumor Necrosis Factor in the Canine Testis, Epididymis and Spermatozoa. Theriogenology, 77, 1540-1548. https://doi.org/10.1016/j.theriogenology.2011.11.021

[15] Joslin, L. (2009) Blood Collection: Technique in Exotic Small Mammals. Journal of exotic Pet Medicine, 18, 117-119. https://doi.org/10.1053/j.jepm.2009.04.002

[16] Al-Serwi, R. and Ghoneim, F. (2015) The Impact of Vitamin E against Acrylamide Induced Toxicity on Skeletal Muscles of Adult Male Albino Rat Tongue: Light and Electron Microscopic Study. Journal of Microscopy and Ultrastructure, 3, 137-147. https://doi.org/10.1016/j.jmau.2015.03.001

[17] El-beltagi, H. and Ahmed, M. (2016) Assessment the Protective Role of Quercetin on Acrylamide-Induced Oxidative Stress in Rats. Journal of Food Biochemistry, 40, 715-723. https://doi.org/10.1111/jfbc. 12262 
[18] Padalko, A., Cristall, N., Gawaziuk, J.P. and Logsetty, S. (2019) Social Complexity and Risk for Pediatric Burn Injury: A Systematic Review. Journal of Burn Care \& Research, 40, 478-499. https://doi.org/10.1093/jbcr/irz059

[19] Cribbs, R.K., Luquette, M.H. and Besner, G.E. (1998) A Standardized Model of Partial Thickness Scald Burns in Mice. Journal of Surgical Research, 80, 69-74. https://doi.org/10.1006/jsre.1998.5340

[20] Ipaktchi, K., Mattar, A., Niederbichler, A., et al. (2014) Attenuating Burn Wound Inflammatory Signaling Reduces Systemic Inflammation and Acute Lung Injury. Journal of immunology, 177, 8065-8071. https://doi.org/10.4049/jimmunol.177.11.8065

[21] Adeteye, O.V., Yama, O.E. and Gbotolorun, S.C. (2011) Third Degree Burns in Female Wister Rats: The Corollary on Estrous Cycle and Ovarian Histo-Architectural Organization. International Journal of Medicine and Medical Science, 3, 256-261.

[22] Sehirli, O., Sener, E., Sener, G., Cetinel, S., Erzik, C. and Yegen, B.C. (2008) Ghrelin Improves Burn-Induced Multiple Organ Injury by Depressing Neutrophil Infiltration and the Release of Pro-Inflammatory Cytokines. Peptides, 29, 1231-1240. https://doi.org/10.1016/j.peptides.2008.02.012

[23] Xiao, Y.Q., Zhang, F. and Xia, Z.F. (2016) A Mouse Model of Scald Wounds. Austin Journal of Emergency and Critical Care Medicine, 3, 1047-1053.

[24] Tiwari, V.K. (2012) Burn Wound: How It Differs from Other Wounds? Indian Journal of Plastic Surgery, 45, 364-373. https://doi.org/10.4103/0970-0358.101319

[25] Kubo, H., Hayashi, T., Ago, K., et al. (2014) Temporal Expression of Wound Healing Related Genes in Skin Burn Injury. Legal Medicine, 16, 8-13. https://doi.org/10.1016/j.legalmed.2013.10.002

[26] Bortolin, J.A., Quintana, H.T., Tomé, T.C., Ribeiro, F.A., Ribeiro, D.A. and Oliveira, F. (2016) Burn Injury Induces Histopathological Changes and Cell Proliferation in Liver of Rats. World Journal of Hepatology, 8, 322-330. https://doi.org/10.4254/wjh.v8.i6.322

[27] Jayaraman, A., Maguire, T., Vemula, M., Kwon, D.W., Vannucci, M., Berthiaume, F. and Yarmush, M.L. (2009) Gene Expression Profiling of Long-Term Changes in Rat Liver Following Burn Injury. Journal of Surgical Research, 152, 3-17, 17.e1-2. https://doi.org/10.1016/j.jss.2007.05.025

[28] Farina, J.A., Rosique, M.J. and Rosique, R.G. (2009) Curbing Inflammation in Burn Patients. International Journal of Inflammation, 2009, Article ID: 715645.

[29] Jeschke, M.G. (2009) The Hepatic Response to Thermal Injury: Is the Liver Important for Postburn Outcomes? Molecular Medicine, 15, 337-351. https://doi.org/10.2119/molmed.2009.00005

[30] Colton, B., Nielson, C.B., Duethman, N.C., Howard, J.M., Moncure, M. and Wood, J.G. (2017) Burns: Pathophysiology of Systemic Complications and Current Management. Journal of Burn Care \& Research, 38, e469-e481. https://doi.org/10.1097/BCR.0000000000000355

[31] Ramzy, P., Wolf, S., Irtun, O., Hart, D.W., Thompson, J.C. and Herndon, D.N. (2000) Gut Epithelial Apoptosis after Severe Burn: Effects of Gut Hypoperfusion. Journal of the American College of Surgeons, 190, 281-287. https://doi.org/10.1016/S1072-7515(99)00269-0 